\title{
FEATURES OF ELECTRICITY DISTRIBUTION USING ENERGY STORAGE IN SOLAR PHOTOVOLTAIC STRUCTURE
}

\author{
Y. Veremiichuk ${ }^{1}$, O. Yarmoliuk ${ }^{1}$, A. Pustovyi ${ }^{1}$, \\ A. Mahnitko ${ }^{2}$, I. Zicmane ${ }^{2 *}$, T. Lomane ${ }^{2}$ \\ ${ }^{1}$ National Technical University of Ukraine \\ "Igor Sikorsky Kyiv Polytechnic Institute", \\ 37, Prosp. Peremohy, Kyiv, 03056, UKRAINE \\ ${ }^{2}$ Riga Technical University, Institute of Power Engineering, \\ 12/1, Azenes Str., Riga, LV-1048, LATVIA \\ *e-mail: zicmane@eef.rtu.Iv
}

The intensive development of renewable energy, especially solar power and wind power plants, poses risks of disrupting the balance reliability of the grid. There is the need to develop electricity storage system area, first of all, due to the global tendency to increase the demand for electricity and the number of electricity generation from renewable sources. The issue of guaranteeing electricity supply to the consumer operating in the autonomous renewable source - energy storage device - consumer system is the main criterion when selecting the installed capacity of the generator on the basis of renewable sources and energy storage device capacity. Also, the application does not allow reducing voltage fluctuations in the renewable sources - the consumer system.

Keywords: Energy storage, rechargeable batteries, renewable energy, solar photovoltaic.

\section{INTRODUCTION}

The past decade has seen strong growth in the deployment of renewable energy technologies, with the power sector leading the way thanks to sharp cost reductions for solar photovoltaic (PV) and wind power. In the Stated Policies Scenario [1], nearly $8500 \mathrm{GW}$ of new power capacity is added globally by 2040 , of which twothirds is renewables. Renewables account for the majority of capacity grows in most regions. This includes about $80 \%$ of additions in the European Union and China, but 
they provide less than half of additions in Southeast Asia and the Middle East. Solar PV provides the largest share of renewable capacity additions in most regions, including China and India.

In the Sustainable Development Scenario, renewables account for around $80 \%$ of capacity additions in all regions, complemented mainly by nuclear power and carbon capture technologies.

Globally, electricity demand is projected to grow by over $20 \%$ over the next decade, but flexibility - the ability of the power system to quickly adapt to changes in power supply and demand - will grow by some $80 \%$. Flexibility will therefore be the cornerstone of future electricity systems. It will be met not only by traditional sources of flexibility - such as conventional power plants and electricity grids - but also by new sources of flexibility, including battery storage and demand-side response, which are projected to grow fast and contribute to 400 GW by 2040 (Fig. 1).

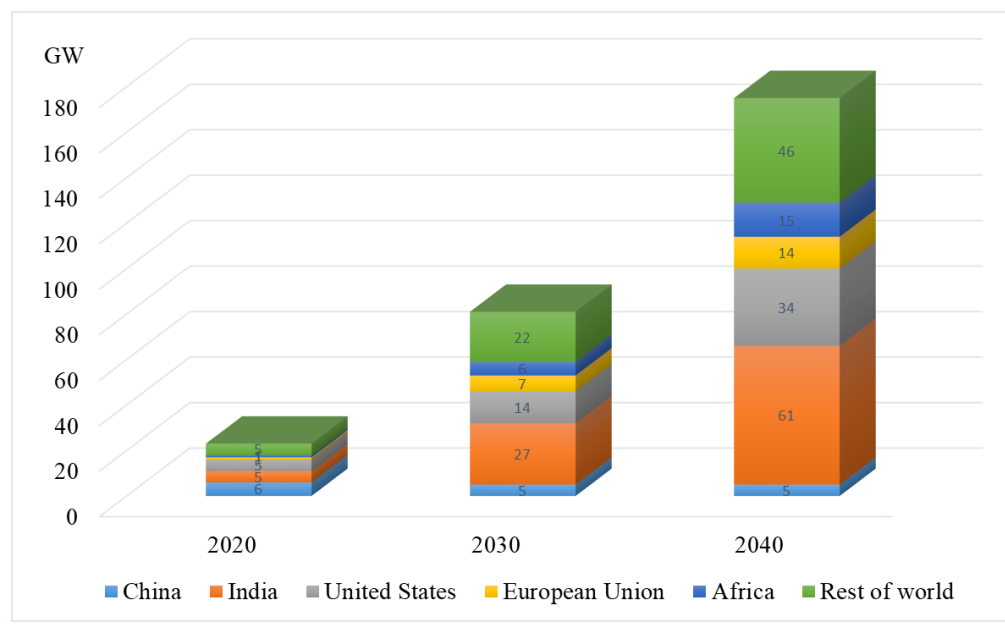

Fig. 1. Installed capacity of utility-scale battery storage systems in the New Policies Scenario, 2020-2040.

Ukraine has not stayed away from world trends. Today, due to the state subsidization of renewable energy sources (RES) electricity producers, there is an intensive development of RES, which are connected to the electricity system at the level of distribution electricity grids, which leads to a gradual transition from a purely centralised (big atomic and fossil fuel power stations) model of electricity supply to combined when part of electricity is generated by dispersed sources.

According to the operational data of the National Energy Commission "Ukrenergo", the total installed capacity was 53042.50 MW in January 2020; RES capa- city was $4949.80 \mathrm{MW}$, and it was distributed according to generation technologies in this ratio (Fig. 2).

The intensive development of renewable energy, especially solar power plants and wind power plants, poses risks of disrupting the balance reliability of the grid. In order to continue the increase of RES share, it is necessary to increase the volume of primary, secondary regulation and substitution reserve.

It is necessary to develop electricity storage systems area, first of all, due to the global tendency to increase the demand for electricity and the number of electricity generation from renewable sources. 
With smooth operation, electrical storage systems will contribute to the stable functioning of the grid, reduce network imbalances caused by unbalanced loads from consumers, and maintain the pace of renewable electricity inputs.

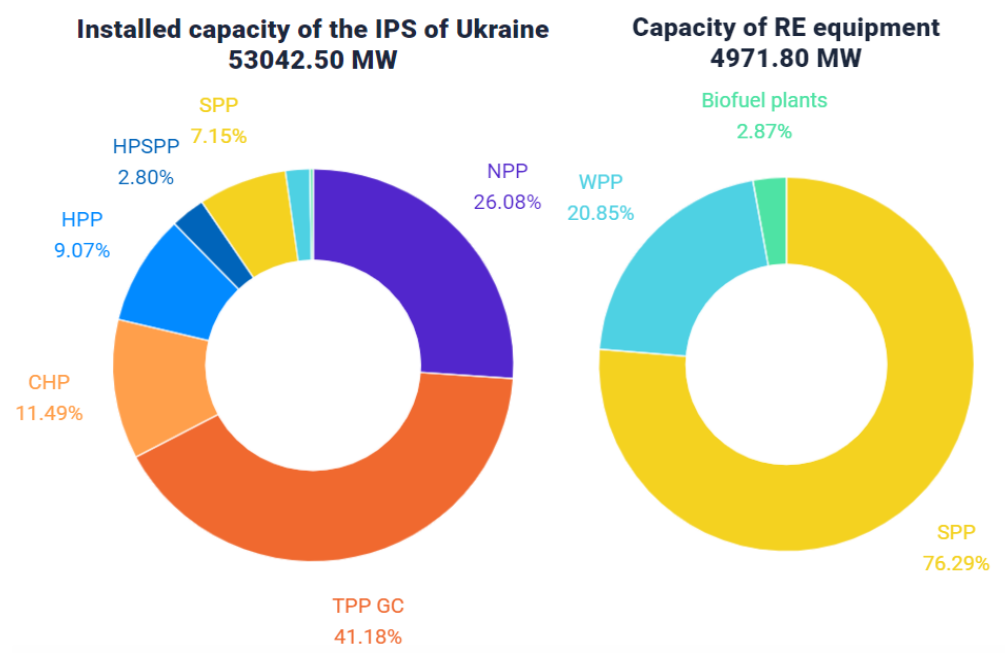

TPP GC - energy generating companies of thermal power plants, NPP - nuclear power plants, CHP - combined heat and power, HPP - hydro power plants, HPSPP - hydro pumped storage power plants, $\mathrm{SPP}$ - solar power plants, WPP - wind power plants

Fig. 2. The installed capacity of the integrated distribution system of Ukraine and power of RES equipment [2].

\section{THEORETICAL CALCULATIONS}

The use of RES has a number of positive qualities that ensure their active development. In particular we can determine no environmental pollution during operation, the need for maintenance and others. Along with the positive properties, there are a number of disadvantages, the main of which is the lack of predictability of generation volumes as a time function and the impact on electricity supply security [3]-[5]. However, by integrating an energy storage device (ES) into the system of a generating set, it can significantly reduce the negative impact of the unpredictable generation factor [6]-[8]. ES application helps accumu- late surpluses generated by RES and use the accumulated energy in times of scarcity and / or lack of generation from RES [9].

The issue of guaranteeing electricity supply to the consumer operating in the autonomous RET-ES-consumer system is the main criterion when selecting the installed capacity of the generator on the basis of RET and ES capacity [10]. Also, the application does not allow reducing voltage fluctuations in the RET-consumer system [11], [12].

Analysing the parameters of modern ES, different types of rechargeable batteries (RB), taking into account the specific 
energy consumption of $30-400 \mathrm{~W} \cdot \mathrm{h} / \mathrm{kg}$ and the number of life cycles of 500-1200, can be considered the most suitable for longterm use in the RES-ES-consumer system. One of the ways to solve the problem of guaranteed electricity supply is to choose ES that allows accumulating all energy excess generated by RES and the consumed load [13], [14]. An important feature of the RES-ES-consumer system is the constant presence of excess generation, which can be used during periods of scarcity and / or absence of RES generation. Determining the ES parameters to cover the needs of the autonomous consumer is important enough and at the same time not sufficiently elaborated. Therefore, the relevant question remains the use of ES in the energy hub [15], which has its own RES and interacts with the grid under different market conditions [16].

It is necessary to consider that there are restrictions that do not allow for the use of all $100 \%$ of stored energy in the RB, which is due to its type [17].

The charge of each RB can be divided into two parts. The first part is the maximum depth of discharge (MDOD) for a certain type of $\mathrm{RB}$, which is a relative value for most types of modern RB. All RB manufacturers and their equipment technical data sheets indicate MDOD as the degree of discharge at which the RB operates the least number of charge / discharge cycles. Though, when the discharge is higher than MDOD, the RB wear rate increases. It will be logical to state that there is a certain relative value of the minimum degree of charge of the RB, which must be permanently stored in the RB MSOC (minimum state of charge). Thus, for each individual type of $\mathrm{RB}$ the following expression can be written:

$$
M S O C+M D O D=1 .
$$

The numerical expression of the energy contained in the RB can be determined by arithmetically multiplying the value of the capacitance RB by the voltage between its terminals. Typically, RB is used to determine the nominal capacity and submit it in $\mathrm{A} \cdot \mathrm{h}$. Therefore, it is more convenient to operate the battery charge level rather than its capacity. Depending on the operating modes that are constantly changing (charge discharge), the charge value (amount of stored energy) changes. Since at each point of time we will have different values of the electric charge $(A \cdot h)$, it can be numerically expressed by the dimensionless SOC (state of charge) ratio of the current charge $\mathrm{RB}$ to its nominal capacity. Next to the SOC, there is a DOD (depth of discharge) ratio of the $\mathrm{RB}$ discharge to its nominal capacity. That is, at any point in time RB can be described by the expression:

$$
S O C(t)+D O D(t)=1 \text {. }
$$

From Eq. (2) it follows that a fully charged RB corresponds to a value $\operatorname{SOC}(t)=1$ and $D O D(t)=0$. Fully discharged RB $-S O C(t)=0$ and $D O D(t)=1$.

From the above we can see that there is a range of charge levels of the $\mathrm{RB}$ in which it will work without failure, let us call it NRM (normal run mode). NRM is a range from full charge RB to MSOC, which can be described as follows:

$$
N R M \in[M S O C ; 1] .
$$

In numerical form, NRM can be defined as follows:

$$
N R M=1-M S O C=M D O D .
$$

The change in SOC at successive time intervals can be expressed as a dependency: 
$\operatorname{SOC}(t)=\operatorname{SOC}(t-1)+\frac{A_{R E S}(t)-\left(A_{\text {load }}^{D C}(t)+\frac{A_{\text {load }}^{A C}(t)}{\eta_{\text {inv }}}\right)}{V_{\text {bat }} C_{\text {bat }}}$

where $A_{R E S}(t)$ - the amount of energy produced by RES, $A_{\text {load }}^{D C(A C)}(t)$ - the amount of energy consumed by the load (the upper indices are applied to DC and AC, respectively), $\eta_{i n v}-$ inverter efficiency, $V_{b a t}-$ voltage at terminals of RB array, $C_{b a t}-\mathrm{RB}$ array capacity.

It should be noted that the selected capacity of the RB array in the entire cycle of operation, with uninterrupted supply of electrical energy to the load, should be in the charged state. This statement can be represented by the expression:

$$
\forall S O C(t)=M S O C \text {. }
$$

The RB state can be described by the dependence of the SOC invariance criterion:

$$
\operatorname{SOC}\left(t_{0}\right)=\operatorname{SOC}\left(t_{T}\right)
$$

Depending on Eq. (7), the start of the RES work period with RB is the beginning of the calculation cycle. Taking into account Eq. (7), the dependence (5) will be

$$
\operatorname{SOC}\left(t_{T}\right)=\operatorname{SOC}\left(t_{0}\right)+\frac{A_{R E S}(t)-\left(A_{\text {load }}^{D C}(t)+\frac{A_{\text {load }}^{A C}(t)}{\eta_{\text {inv }}}\right)}{V_{\text {bat }} C_{\text {bat }}}
$$

The condition (7), with (8), gives the dependence:

$$
\sum_{t=t_{i}}^{t_{T}}\left[A_{R E S}(t)-\left(A_{\text {load }}^{D C}(t)+\frac{A_{\text {load }}^{A C}(t)}{\eta_{\text {inv }}}\right)\right]=0 .
$$

Dependence (9) makes it possible to determine the necessary value for $A_{R E S}(t)$ and to choose the appropriate hardware for its implementation according to the consumer's needs.

Using dependence (9) in this case it is possible to determine the number of photovoltaic panels of a certain type that will provide the production of electrical energy in volume depending on consumption.

Since it changes randomly, the energy accumulated / transmitted by the RB can be determined when equality (9) is not fulfilled in relation to (7), i.e. an excess / deficit of electrical energy produced by RES. The energy $A_{R E S}(t)$ accumulated / released by $\mathrm{RB}$ can be determined according to (9) by the dependence of:

$$
A_{b a t}(t)=A_{R E S}(t)-A_{\text {load }}^{D C}(t)+\frac{A_{\text {load }}^{A C}(t)}{\eta_{\text {inv }}} .
$$

Dependence (10) makes it possible to determine the RB capacitance, if it is con- 
stant, by dividing the right and left portions of this dependence by $V_{b a t} C_{b a t}$. However, according to the research, it is known that depending on the charging current $\left(I^{+}\right) \mathrm{RB}$ will have a different capacity; depending on the state of charge $S O C(t)$, the voltage at $\mathrm{RB}$ array terminals will vary. The capacity of the RB also changes under the influence of the ambient temperature and the lifetime - degradation of the active substances of the RB.

For further use of dependence (10), it is necessary to neglect influencing factors on the result of the RB capacitance value volatility. Therefore, the capacitance of the $\mathrm{RB}$ is considered to be the amount of energy that $\mathrm{RB}$ contains. We will estimate the amount of this energy by determining the RB charge $-Q(t)$.

The amount of energy that an RB array contains at any given time can be regarded as dependent on the $S O C(t)$. In numerical terms:

$Q(t)=C_{b a t} S O C(t)$.
In Eq. (8), $C_{b a t}$ means the current value of the RB capacitance, which cannot be determined during operation.

At each point in time, the RB charge will determine the sum of two components: RB charge at the start of the operation $Q\left(t_{0}\right)$ and all stored energy in the RB at the current time. According to (8) and (10), the following dependence can be obtained:

$$
Q(t)=Q\left(t_{0}\right)+\sum_{t=t_{i}}^{t_{T}} \frac{A_{b a t}}{V_{b a t}} .
$$

The value of $Q(t)$ according to (12) must be greater, which corresponds only to the fully charged RB state. Achieving this condition is possible by accordingly choosing the value of $Q\left(t_{0}\right)$.

During the whole period of RES operation, depending on the produced energy volume, the RB charge value according to formula (12) may vary from $Q_{\min }$ to $Q_{\max }$. These values can be determined from all the calculated value series as follows:

$$
Q_{\min }=\min (Q(t)), \quad Q_{\max }=\max (Q(t)), \quad t=\left[t_{1}, t_{2} \ldots t_{T}\right] .
$$

Since the $Q_{\min }$ value must be positive (subject to a constant charge array RB), the minimum charge and the value of the operating range selected as a result $C_{b a t}$ must meet the following conditions:

$$
\begin{aligned}
& Q_{\min } \geq D O D C_{\text {bat }}, \\
& Q_{\max }-Q_{\min } \geq N R M C_{\text {bat }} .
\end{aligned}
$$

Taking into account Eqs. (14) and (15), we obtain a two-criterion equation:

$$
C_{b a t} \geq \max \left[\frac{Q_{\max }-Q_{\min }}{N R M}, \frac{Q_{\min }}{M S O C}\right] .
$$

The calculation according to dependence (16) can be performed in case of existing consumer's electric load schedule and forecast / statistics on RES electricity generation. The calculation should be performed for typical periods of RES-RB complex use depending on the time of the year, working days and days off, etc. Particular attention should be paid to ensuring that the charge / discharge current RB is limited. The value of the RB capacity according to the calculation results should satisfy all selected periods of the RES-RB complex usage. 


\section{EXPERIMENTAL RESULTS}

Let us calculate the choice of ES power in which the SPP is integrated (Fig. 3). for the distribution electrical network area,

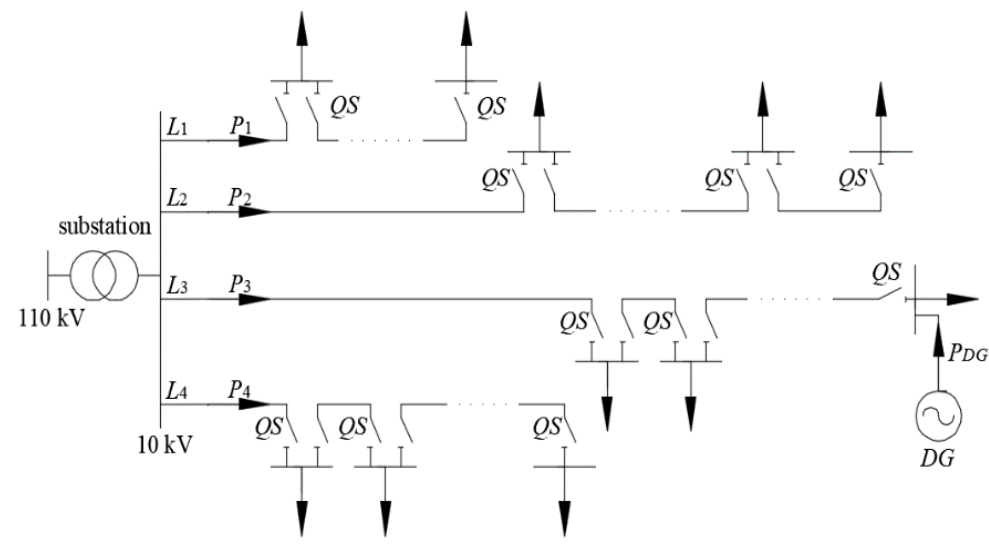

Fig. 3. An example of distribution electrical network area.

The 110/10 kV electrical substation supplies four $10 \mathrm{kV} L_{1}-L_{4}$ distribution lines, the load of which is modelled by the built-in random number function in MS Excel software.

The calculation carried for ES power choice for two scenarios:

- integrated distribution system (IDS) sets limits on the possible SPP generation power flow through a $110 / 10 \mathrm{kV}$ substation;

- IDS sets a load schedule requirement for the distribution network area under consideration.

Consider a situation where IDS sets a limit on the possible flow of excess SPPgenerated power through a substation. Let us analytically show this by the following expression:

$P_{S u b}=P_{1}+P_{2}+P_{3}+P_{4}-P_{D G} \geq 0$,

where $\mathrm{P}_{1}, \mathrm{P}_{2}, \mathrm{P}_{3}, \mathrm{P}_{4}$ are the load of the $10 \mathrm{kV}$ distribution lines $L_{1}, L_{2}, L_{3}$ and $L_{4}$, respectively, $\mathrm{kW} ; \mathrm{P}_{D G}$ is the power generated by the SPP integrated into the distribution network, $\mathrm{kW}$.

Under condition (2), for the considered area of the distribution network an electricity accumulator (EA) will accumulate undelivered (surplus) electricity SPP with the possibility of further release within the IDS limit set.

The amount of electricity $A$ released for a certain period of time $\Delta t$ into the distribution network is calculated by the expression:

$$
A_{i}=P_{i} \Delta t
$$

The total load of the distribution network of $10 \mathrm{kV}$ area and the SPP generation schedule, which is integrated into the grid, are shown in Fig. 4. The SPP generation schedule is taken from the existing station and the electricity generated from the grid is calculated using Eq. (18).

During the day, the distribution network ( $L_{1}-L_{4}$ lines) consumed $A_{S u b}=20893 \mathrm{kWh}$ and generated SPP $-\mathrm{ADG}=17753.03 \mathrm{kWh}$. 


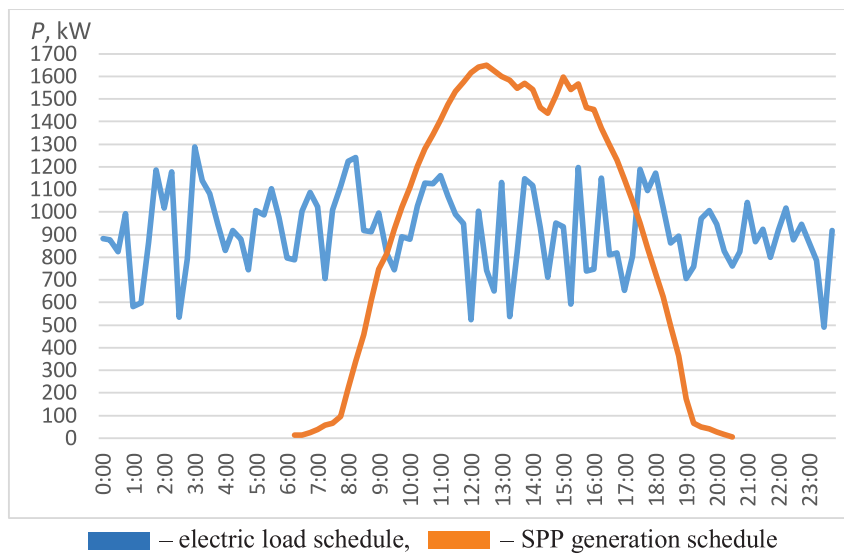

Fig. 4. Graph plots of total distribution network load and SPP generation for one day.

To obtain the data on the $10 \mathrm{kV}$ substa- distribution network, Eq. (19) is used. tion busbar load, taking into account the generation of SPP that is integrated into the $\quad P_{S u b}=P_{1}+P_{2}+P_{3}+P_{4}-P_{D G}$

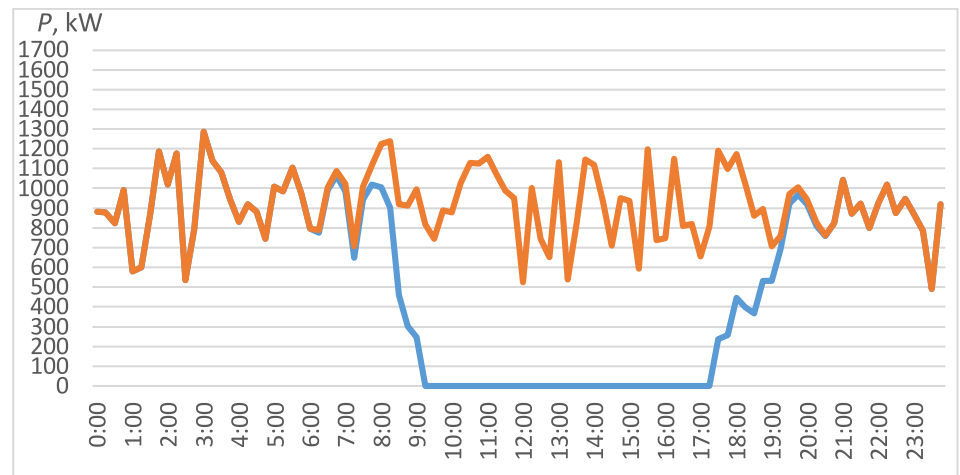

- electrical load schedule,

- electrical load schedule considering SPP generation

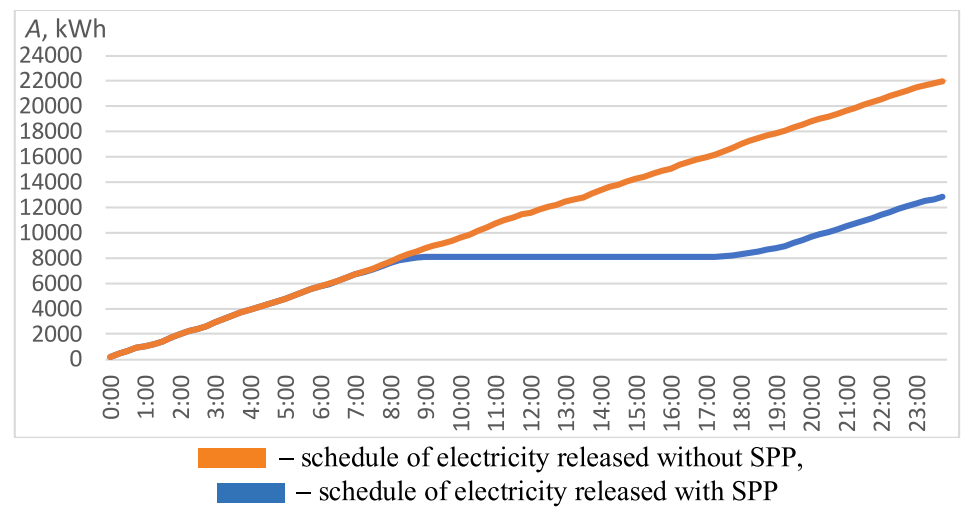

Fig. 5. Graph plots of electricity consumption, taking into account the IDS constraints and sufficient SPP generation ( $a$ - timetable for the IDS limitation on power flow; $b$ - comparative graph of electricityconsumption with and without SPP in selected grid area). 
The integration of the SPP into the distribution network area under consideration (Fig. 3) has a significant impact on the $10 \mathrm{kV}$ substation busbar load. In the absence of SES, the amount of electricity released from the $10 \mathrm{kV}$ substation busbar into the network per day was $20893 \mathrm{~kW} \cdot \mathrm{h}$, and with the appearance of the SPP $-7578.23 \mathrm{~kW} \cdot \mathrm{h}$.

Taking into account the IDS constraints and sufficient SPP generation, which from 10.00 to 17.00 can completely satisfy the electricity needs of the distribution network area, there is possibility and necessity of generated electricity accumulation from SPP. Graphically, it is demonstrated in Fig. 5.

The total amount of accumulated electricity in EA will be $4174.756 \mathrm{~kW} \cdot \mathrm{h}$ per day.

In the presented case, when the IDS establishes a restriction on the possible power flow (excess of SPP generated power) through the substation, the EA power should be selected based on the data obtained on the total accumulated electricity per day. In this situation, the EA power should not be less than $4174.756 \mathrm{~kW} \cdot \mathrm{h}$, this value is brought to the nearest standard $4200 \mathrm{~kW} \cdot \mathrm{h}$.

Let us consider the second scenario, in which the IDS sets a load schedule requirement for the distribution network area (Fig. 3).

The minimum value of electrical load is $P_{\text {min }}=540.1 \mathrm{~kW}$ and accordingly the maximum value is $P_{\max }=1160.1 \mathrm{~kW}$. The total amount of electricity released by the $10 \mathrm{kV}$ substation busbar should be $20816.5 \mathrm{~kW} \cdot \mathrm{h}$ per day.

In order to comply with the established load schedule (Fig. 6), the $10 \mathrm{kV}$ substation busbar, which is the power supply point for the four lines and the SPP, EA must be integrated into the SPP structure.

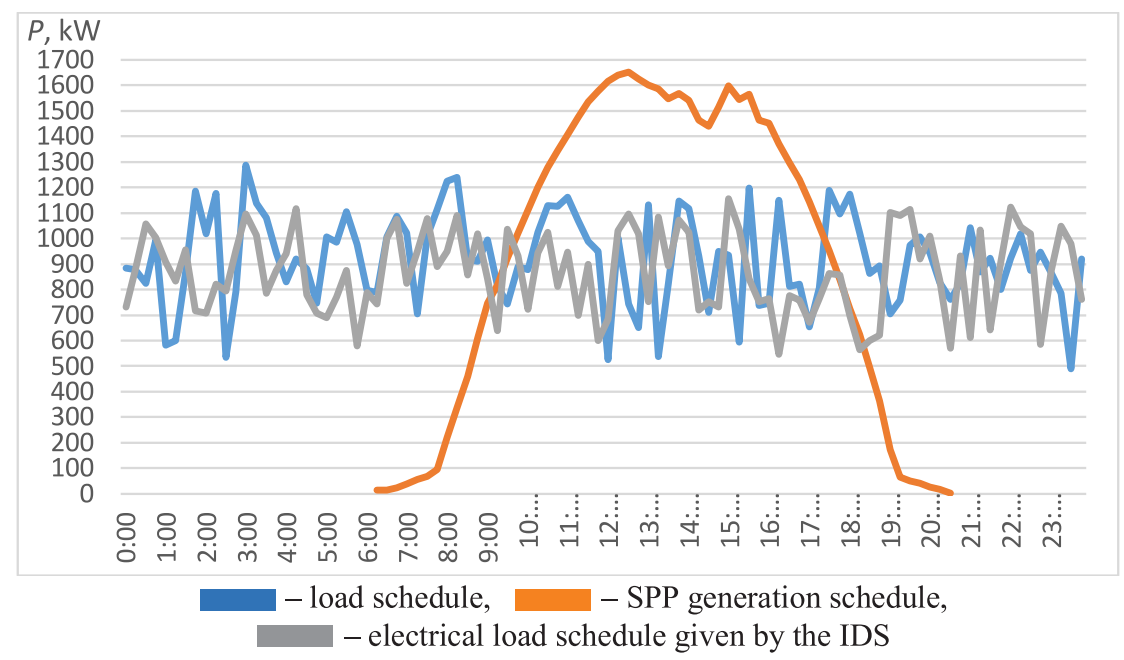

Fig. 6. Combined load and generation schedule for the distribution network area.

We calculate the load at time moment on EA terminals by Eq. (20).

$$
P_{\mathrm{HE}}=P_{\text {Sub }}-P_{1}-P_{2}-P_{3}-P_{4}+P_{D G} \text {. }
$$

Taking into account the limitation on electricity consumption from the $10 \mathrm{kV}$ substation busbar (Fig. 6), Fig. 7 shows the "charge-discharge" process of an electric drive for balancing in the selected distribution network area. 

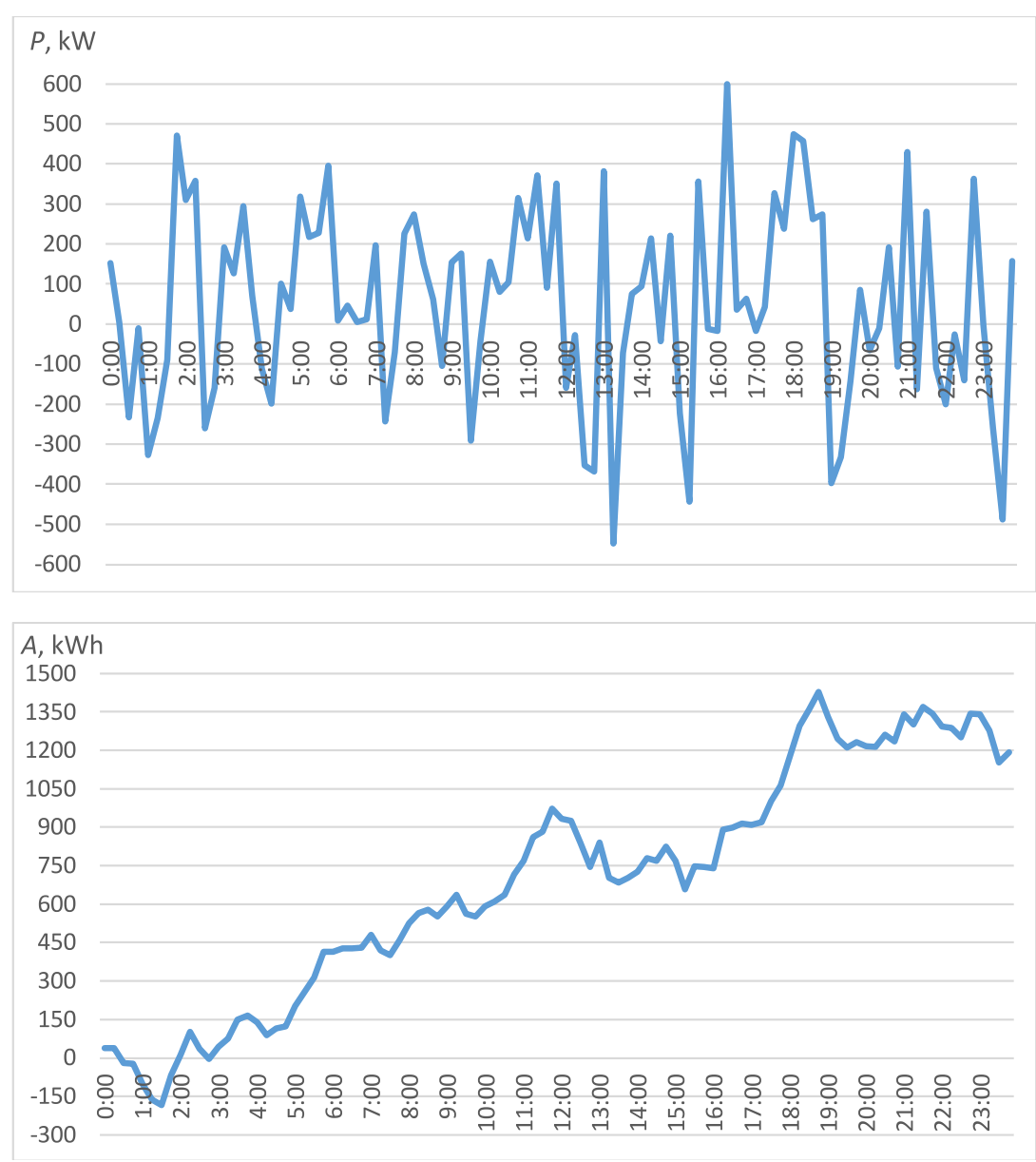

Fig. 7. EA charge and discharge process ( $\mathrm{a}$ - power; $\mathrm{b}$ - electricity amount).

Figure 7a demonstrates both positive and negative power values. Positive values reflect the EA charge process due to the appearance of excess power, and negative values reflect the EA discharge process due to the system power lack.

After analysing the given data and the EA work schedule, its charge and discharge are $Q_{\max }=\grave{A}_{\max }=1428.5 \mathrm{~kW} \cdot \mathrm{h}$, $Q_{\text {min }}=\grave{A}_{\min }=-184.5 \mathrm{~kW} \cdot \mathrm{h}$.

Based on the values of charge and discharge, it is possible to calculate the required EA power using Eq. (16):

$$
\begin{aligned}
& \mathrm{A}_{\mathrm{EA}} \geq \max \left[\frac{Q_{\max }-Q_{\min }}{N R M}: \frac{Q_{\min }}{M S O C}\right]= \\
& =\max [1792.22 ;-1845]=1792.22 \mathrm{kWh} .
\end{aligned}
$$

As a result of the calculation, the optimum EA standard power can be selected:

$$
\mathrm{A}_{\mathrm{EA}}=1800 \mathrm{~kW} \cdot \mathrm{h} .
$$

The various renewable energy sources that use energy storage in their structure can be considered the integrated power systems for expanding the network node in the electricity grid. Developing and implementing approaches to optimize the functioning of such energy hubs are a promising project in the context of sustainable development of Ukraine's energy sector. 
The use of renewable energy sources in the grid imposes certain features on IDS operation, in part of electricity consumption mode formation and can be implemented using probabilistic prediction methods and algorithms of artificial neural networks.

The use of energy storage will allow RES entities to comply with IDS requirements regarding electricity losses, which will, as a result, meet the operational safety standards of the electricity grids.
Using the procedure of the optimal capacity calculating for the complex "renewable source-battery", for each scenario EA optimal power allows providing the optimum quality of electricity. The simulation also found that the load schedule constraints for the PV distribution area required less energy storage than the restriction on the possible power flow.

\section{REFERENCES}

1. International Energy Agency. (n.d.). Available at https://www.iea.org/reports/ world-energy-outlook-2019/

2. Installed Capacity of the IPS of Ukraine and Capacity of Renewable Energy Equipment. (n.d.). Available at https://ua.energy/ installed-capacity-of-the-ips-of-ukraine/

3. Du, E., Zhang, N., Hodge, B.-M., Wang, Q., Lu, Z., Kang, C., \& Xia, Q. (2018). Operation of a High Renewable Penetrated Power System with CSP Plants: A Look-ahead Stochastic Unit Commitment Model. IEEE Transactions on Power Systems, 34 (1), 140-151. Doi:10.1109/ tpwrs.2018.2866486.

4. Hui, G., Tiejun, L., Xin, S., Hong, Y., \& John, M.C. (2016). Energy-efficient resource allocation for massive MIMO amplify-and-forward relay systems. In 16th International Conference on the European Energy Market, 2016 (pp. 2771-2787). Doi: 10.1109/ACCESS.2016.2570805.

5. Veremiichuk, Y., Zamulko, A., Zaichenko, S., Mahnitko, A., Berzina, K., \& Zicmane, I. (2018). Analysis of electric energy supply security attached to renewable energy sources implementation. In X International Conference on Electrical and Power Engineering (pp. 0977-0981), 18-19 October 2018. Iaşi, Romania.
6. Wang, Z., Luo, D., Li, R., Zhang, L., Liu, C., Tian, X., \& He, J. (2017). Research on the active power coordination control system for wind/photovoltaic/energy storage. In IEEE Conference on Energy Internet and Energy System Integration, 26-28 November 2017. Beijing, China. Doi:10.1109/ei2.2017.8245403.

7. Wang, X., \& Liu, Y. (2017). Analysis of energy storage technology and their application for micro grid. In International Conference on Computer Technology, Electronics and Communication, 1921 December 2017. Dalian, China. Doi:10.1109/icctec.2017.00215.

8. Berry, I., \& Heinzmann, J.(2016). Economics of energy storage for dispatchable solar. In IEEE Power and Energy Society General Meeting, 17-21 July 2016. Boston, USA. Doi:10.1109/pesgm.2016.7741165.

9. Yakymenko, Y.I., Sokol, Y.I., Zhuikov, V.I., Peterheria, Y.S., \& Ivanin, O.L. (2001). Renewable energy at local sites. Ukraine: Kyiv: Polytechnics.

10. Kleinberg, M., Mirhosseini, N.S., Farzan, F., Hansell, J., Abrams, A., Katzenstein, W., \& Jafari, M.A. (2014). Energy Storage Valuation under Different Storage Forms and Functions in Transmission and Distribution Applications. Proceedings of 
the IEEE, 102 (7), 1073-1083. Doi:10.1109/ jproc.2014.2324995.

11. Zaharov, A.M. (2014). Reduction of Voltage Deviations at Places of Connection of Powerful Solar Power Plants to Power Grids. Tekhnichna elektrodynamika, 5, 4446.

12. Hao, C., Yanbing, J., Jin, Z., Yanfang, Z., Gang, L., \& Dong, X. (2019). Energy storage frequency regulation energy management strategy based on k-means analysis. In IEEE 3rd International Conference on Green Energy and Applications, 16-18 March 2019. Taiyuan, China. Doi:10.1109/ icgea.2019.8880782.

13. Jing, Li.J., Wei, W., \& Xiang, J.A. (2012). Simple Sizing Algorithm for Stand-Alone PV/Wind/Battery Hybrid Microgrids. Energies, 5, 5307-5323.

14. Ponnambalam, K., Saad, Y.E., Mahootchi, M., \& Heemink, A.W. (2010). Comparison of methods for battery capacity design in renewable energy systems for constant demand and uncertain supply. In 7 th International Conference on the European Energy Market, 23-25 June 2010. Madrid, Spain. Doi:10.1109/eem.2010.5558745.
15. Veremiichuk, Y., Prytyskach, I., Yarmoliuk, O., \& Opryshko, V. (2019). Energy sources selection for industrial enterprise combined power supply system. In IEEE 6th International conference on Energy Smart Systems, 17-19 April 2019 (pp. 283-288). Ukraine, Kyiv.

16. Veremiichuk, Y. Berzina, K., Zicmane, I., Mahnitko, A., \& Patel, D.K. (2019). Optimal Power Flow in Power System in Latvian Market Conditions. International Multidisciplinary Scientific GeoConference Surveying Geology and Mining Ecology Management, 19 (4.1), 369-375.

17. Root, C., Presume, H., Proudfoot, D., Willis, L., \& Masiello, R. (2017). Using battery energy storage to reduce renewable resource curtailment. In IEEE Power \& Energy Society Innovative Smart Grid Technologies Conference, 23-26 April 2017. Washington, USA. Doi:10.1109/ isgt.2017.8085955. 